\title{
Datos personales y Cloud Computing
}

\author{
López Martínez, Amelia; Gadea Raga, Alejandro. Servei de Biblioteques i Documentació \\ Universitat de València \\ XV Workshop REBIUN. Castelló, 29-30 setembre 2016
}

\section{Cloud Computing}

Servicios de tratamiento de la información a través de Internet. El proveedor ofrece sus servicios desde cualquier parte del mundo:

- Deslocalización

- Compartición de recursos y movilidad

- Subcontrataciones adicionales

\section{Tipología}

- Nube pública

- Nube privada

- Otros modelos:

híbridas, comunitarias

\section{Modalidades}

- IAAS: Infraestructura como servicio

- PAAS: Plataforma como servicio

- SAAS: Software como servicio

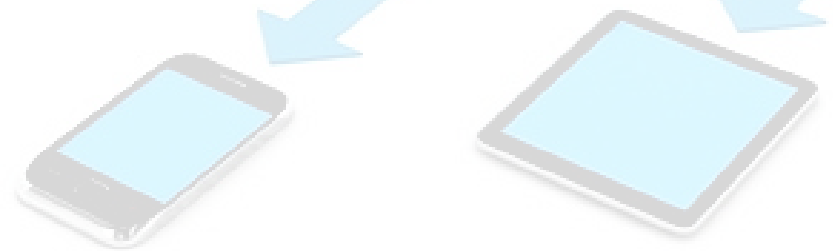

Ventajas e inconvenientes

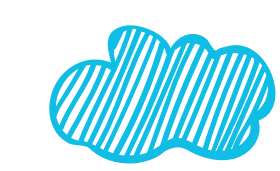

- Independencia

- Coste

- Escalabilidad y elasticidad

- Infraestructuras

- Mantenimiento

- Almacenamiento

\section{Obligaciones como clientes}

- ¿Intervienen terceras empresas?

- Dar conformidad a su participación

- Conocerlas (web)

- Proveedor: en el contrato asume que terceros ofrecen garantías jurídicas

- Contrato: cláusulas para la protección de los datos personales

\section{Precauciones}

- Ubicación

- Transferencias internacionales de datos

- Medidas de seguridad. Certificación de seguridad, auditoría

- Compromisos de confidencialidad

- Portabilidad

- Extinción de contrato

- Derechos ARCO

\section{Tener en cuenta}

- Contrato (art. 12 de la LOPD y art. 20 a 22).

- Prestador = encargado de tratamiento.

- Devolución o destrucción de los datos.

- Subcontratación de servicios.

- Medidas técnicas y organizativas previstas.

- Portabilidad: formatos estandarizados.

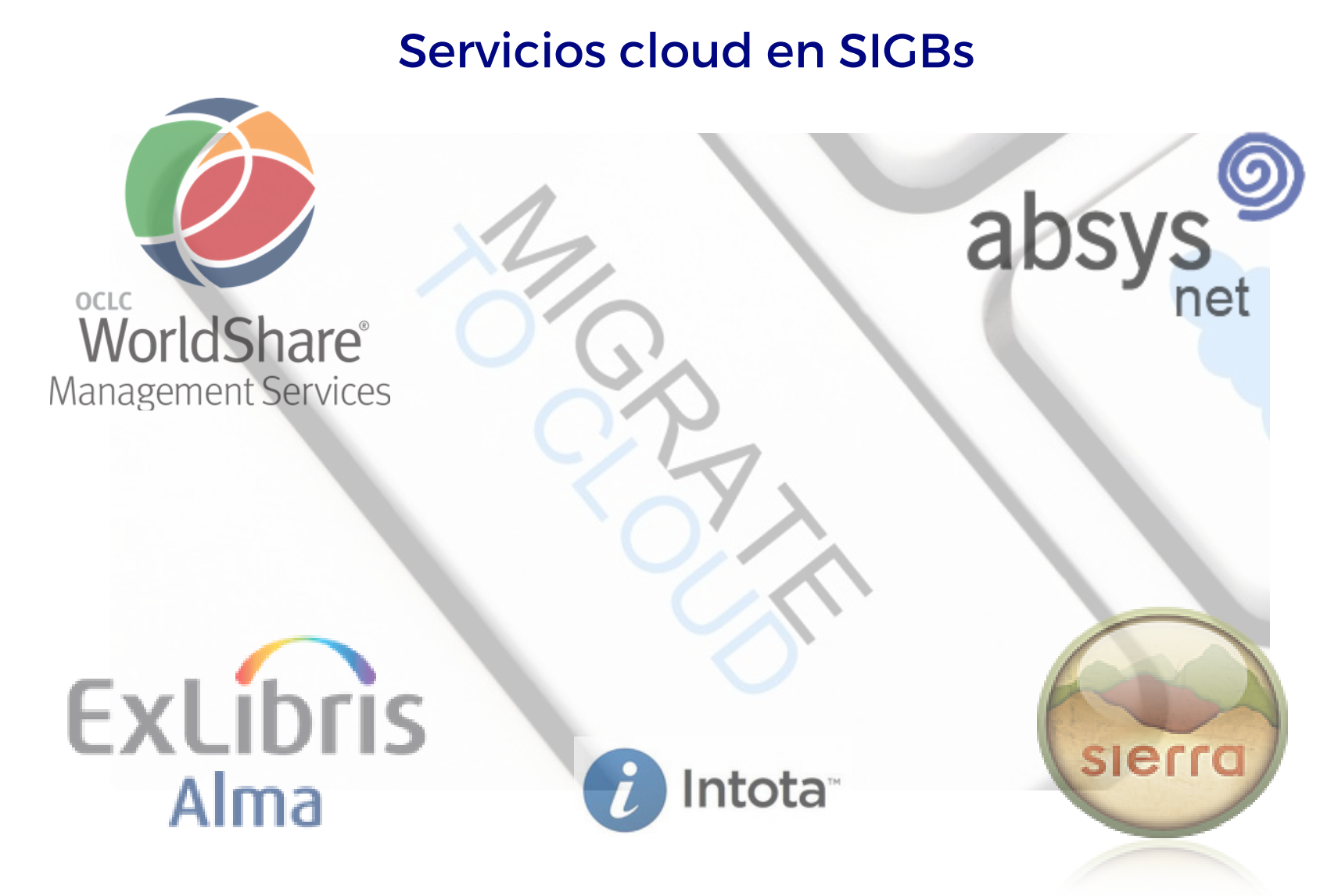

Conocer antes de contratar

- Evaluar los tratamientos y el nivel de protección de datos.

- Verificar las condiciones en las que se presta el servicio.

- Cliente responsable del tratamiento de los datos personales.

- El prestador de servicios es el "encargado del tratamiento" según la LPD.

\section{Legislación aplicable}

- Ley orgánica 15/1999, de 13 de diciembre y Reglamento de desarrollo -RLOPD- aprobado por R.D. 1720/2007.

- La aplicación de la legislación española no puede modificarse contractualmente.

- Datos personales disociados: no cambian la ley aplicable ni las responsabilidades.

- Mayo 2018: LOPD se adaptará a Reglamento General de Protección de Datos de la UE

\section{Administraciones públicas}

- Riesgos específicos implican cautelas adicionales.

- Terceros países podrían solicitar y acceder a la información sin que se informe.

- Marco legal específico:

- Ley de contratos del Sector Público (RD Legislativo 3/11, de 14 de noviembre).

- Ley 11/2007 de Acceso Electrónico de los Ciudadanos a los Servicios Públicos, y RD 167172009 que desarrolla parcialmente esta ley.

- Esquema Nacional de Seguridad (ENS) y Esquema Nacional de Interoperabilidad (ENI) (RD 3/2010 y 472010, de 8 de enero).

Bibliografía

- AEPD (2013). Guía para clientes que contraten servicios de Cloud computing

- Breeding, M. (2012). Cloud computing for libraries. Chicago: ALA TechSource

- Comisión Europea (2016). Online Platforms: contrasting perceptions of European stakeholders. Luxembourg, Publications Office of the EU

- Zimmer, M. (2015). Privacy and cloud computing in public libraries: the case of BiblioCommons. En iConference 2015 proceedings 